Article

\title{
Conjugate Addition of Grignard Reagents to Thiochromones Catalyzed by Copper Salts: A Unified Approach to Both 2-Alkylthiochroman-4-One and Thioflavanone
}

\author{
Tania J. Bellinger ${ }^{1}$, Teavian Harvin ${ }^{1}$, Ti'Bran Pickens-Flynn ${ }^{1}$, Nataleigh Austin ${ }^{1}$, \\ Samuel H. Whitaker ${ }^{1}$, Mai Ling C. Tang Yuk Tutein ${ }^{1}$, Dabria T. Hukins ${ }^{1}$, Nichele Deese ${ }^{1}$ and \\ Fenghai Guo ${ }^{1,2, *(\mathbb{D})}$ \\ 1 Department of Chemistry, Winston Salem State University, 601 S. Martin Luther King Jr. Dr., \\ Winston Salem, NC 27110, USA; tbellinger115@rams.wssu.edu (T.J.B.); tharvin117@rams.wssu.edu (T.H.); \\ tpickensflynn117@rams.wssu.edu (T.P.-F.); naustin116@rams.wssu.edu (N.A.); \\ swhitaker118@rams.wssu.edu (S.H.W.); mtangyuktutein118@rams.wssu.edu (M.L.C.T.Y.T.); \\ dhukins116@rams.wssu.edu (D.T.H.); ndeese119@rams.wssu.edu (N.D.) \\ 2 Biomedical Research Infrastructure Center, Winston Salem State University, Winston Salem, NC 27110, USA \\ * Correspondence: guof@wssu.edu; Tel.: +01-336-750-3158
}

Academic Editors: Roman Dembinski and Igor Alabugin

Received: 8 April 2020; Accepted: 29 April 2020; Published: 1 May 2020

check for updates

\begin{abstract}
Grignard reagents undergo conjugate addition to thiochromones catalyzed by copper salts to afford 2-substituted-thiochroman-4-ones, both 2-alkylthiochroman-4-ones and thioflavanones (2-arylthiochroman-4-ones), in good yields with trimethylsilyl chloride (TMSCl) as an additive. The best yields of 1,4-adducts can be attained with $\mathrm{CuCN} \cdot 2 \mathrm{LiCl}$ as the copper source. Excellent yields of 2-alkyl-substituted thiochroman-4-ones and thioflavanones (2-aryl substituted) are attained with a broad range of Grignard reagents. This approach works well with both alkyl and aromatic Grignard reagents, thus providing a unified synthetic approach to privileged 2-substituted thiochroman-4-ones and a potential valuable precursor for further synthetic applications towards many pharmaceutically active molecules. The use of commercially available and/or readily prepared Grignard reagents will expedite the synthesis of a large library of both 2-alkyl substituted thiochroman-4-ones and thioflavanones for additional synthetic applications.
\end{abstract}

Keywords: conjugate addition; thiochroman-4-ones; Grignard reagents; thiochromones; thioflavanones; 2-alkylthiochroman-4-ones

\section{Introduction}

The 1,4-conjugate addition reaction of organometallic reagents, including Grignard reagents, is one of the most reliable carbon-carbon bond formation reaction in organic synthesis. [1] Without the addition of catalysts, such as $\mathrm{Cu}$ (I) salts, Grignard reagents usually undergo 1,2-addition to $\alpha$, $\beta$-unsaturated carbonyl compounds. It has been shown that with the addition of $\mathrm{Cu}(\mathrm{I})$ salts, Grignard reagents undergo exclusive 1,4-conjugate addition to carbonyl compounds to afford 1,4-adducts [1,2]. In this investigation, we aimed to develop a unified approach to a broad scope of 2-substituted thiochroman-4-ones by taking advantage of the ease in preparation and the breadth in the scope of Grignard reagents. Sulfur-containing heterocycles are widely present in numerous pharmaceutical active molecules as well as in many bioactive natural products [3-6], with widespread applications in areas, such as material science, biology, medicinal chemistry, and food chemistry, in recent years [7-13]. Although the isosteric replacement of an oxygen atom by a sulfur atom is expected to improve 
the bioavailability and bioactivity [14], sulfur-containing heterocyclic compounds are a much less studied area compared to oxygen-containing heterocycles. Due to their rich biological activities and widespread applications, the development towards an efficient synthesis of sulfur-containing compounds has gradually gained interest. In recent years, sulfur-containing heterocycles have been found to display rich biological activities, such as cytotoxic effects on tumor cells in vitro [15], the in vitro antileishmanial and cytotoxic activities [16], as well as the ability to kill tumor cells by inducing tumor cell apoptosis. [17] Thioflavonoids, the sulfur analogues of flavonoids [18-21], display many biological activities, such as antimicrobial, antioxidant, inhibition of nitric oxide production, and antifungal properties, etc. [22-30]. Many thiochromanone derivatives have been known to be effective bioreductive alkylating agents [25]. Thiochromanones, i.e., thiochroman-4-ones, 2-alkylthiochroman-4-ones, and thioflavanone (2-arylthiochroman-4-ones), have become increasingly valuable synthons and vital precursors in organic synthesis for bioactive thiochromanone derivatives [31-38].

Although the synthesis of sulfur-containing heterocycles is much less explored than oxygen-containing counterparts, increasingly more synthetic approaches to thiochroman-4-ones, thioflavone, thiochromones [39-50], and 2-substituted thiochroman-4-ones have been reported in recent years. The enantioselective synthesis of 2-arylsubstituted thiochromanone via Rh-catalyzed conjugate addition to thiochromones [51] and 2-alkylthiochromanones via the $\mathrm{Cu}$-phosphoamidite-promoted enantioselective conjugate addition pathway has been reported recently [52]. A recent synthetic approach of thioflavanones by regioselective cyclization of 1-(2-benzylthio)phenyl-3-phenyl-2-propen-1-ones has also been published [53]. Other synthetic approaches to 2-substituted thiochroman-4-ones include the hydrogenation of thiochromones [54-56], intramolecular thio-Michael addition [57-63], and Friedel-Crafts acylation of thiopropanoic acid [64]. The synthesis of thiochroman-4-ones and thioflavanones via rhodium-catalyzed alkyne hydroacylation/thio conjugate addition sequence has also been reported [65]. With our interests in heterocycles, including sulfur-heterocycles, we also reported the synthesis of 2-alkylthiochromanones via conjugate addition of lithium dialkylcuprates to thiochromones [66] and a rapid entry to thioflavanones via the conjugate addition of diarylcuprates to thiochromones [67]. While most of these approaches provided efficient approaches to either thioflavanones (2-arylthiochroman-4-ones) or 2-alkylthiochromanone, there is a need for a unified approach that works well in introducing both the aliphatic and aromatic groups to furnish the desired 2-alkylthiochroman-4-ones $\mathbf{2}$ and thioflavanones (2-arylthiochroman-4-ones 3). In pursuit of a unified approach of a broad scope of 2-substituted thiochroman-4-ones $\left(2, R_{1}=\right.$ alkyl and $3, R_{1}=A r$; Figure 1$)$ by taking advantage of the readily available and/or readily prepared Grignard reagents, both alkyl and aryl Grignard reagents, we now report the conjugate addition of Grignard reagents to thiochromones $\mathbf{1}$ to afford 2-substituted thiochroman-4-ones $\mathbf{2}$ and $\mathbf{3}$ in good yields using copper salts (Figure 1). This approach will allow access to a broader scope of thiochromanones and thioflavanones due to the readily available Grignard reagents compared to organolithium reagents.
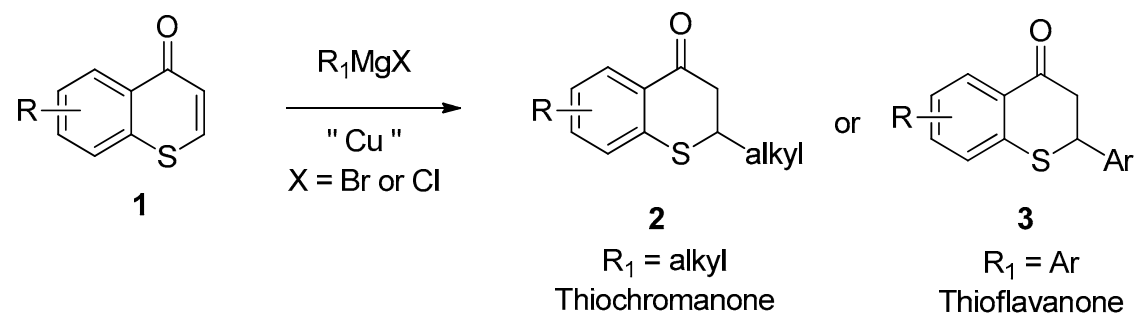

Figure 1. Copper-catalyzed conjugate addition of Grignard reagents to thiochromones.

\section{Results and Discussions}

Our investigation started with $n$-BuMgCl to find the optimal reactional condition for 1,4-conjugate addition to thiochromone with copper salts. Our previous report showed that a Lewis acid activator, 
such as TMSCl, was needed in the conjugate addition of organolithium reagents to thiochromones using a stoichiometric amount of copper salts as no desired 1,4-adducts were observed in the absence of a Lewis acid activator [66,67]. A modest yield of 1,4-adduct 2- $n$-butylthiochroman-4-one 2Aa was formed with $n$ - $\mathrm{BuMgCl}$ and a 0.2 equivalent of $\mathrm{CuI}$ or $\mathrm{CuCN}$ with TMSCl as the activator (Scheme 1 , entries 1-2). The use of $\mathrm{CuCl}$ did not improve the yield (Scheme 1, entry 3). With the addition of $\mathrm{LiCl}$ to $\mathrm{CuCN}$, an excellent yield of 2-n-butylthiochroman-4-one 2Aa was achieved in the presence of TMSCl (Scheme 1, entry 5,89\%). Other Lewis acids, such as TMSOTf, TMSI, and BF 3 . $\mathrm{OEt}_{2}$, also activated this reaction but were not better activators than TMSCl as they did not offer better yields (Scheme 1, entries 6-8). These results show that the use of 0.2 equivalent of $\mathrm{CuCN} \cdot 2 \mathrm{LiCl}$ and TMSCl offered the highest yield. We also found that $\mathrm{CuCN} \cdot 2 \mathrm{LiCl}$ can be further reduced to 0.1 equivalent and a comparable yield of 2 Aa could be attained (Scheme 1, entry 9, 85\%).

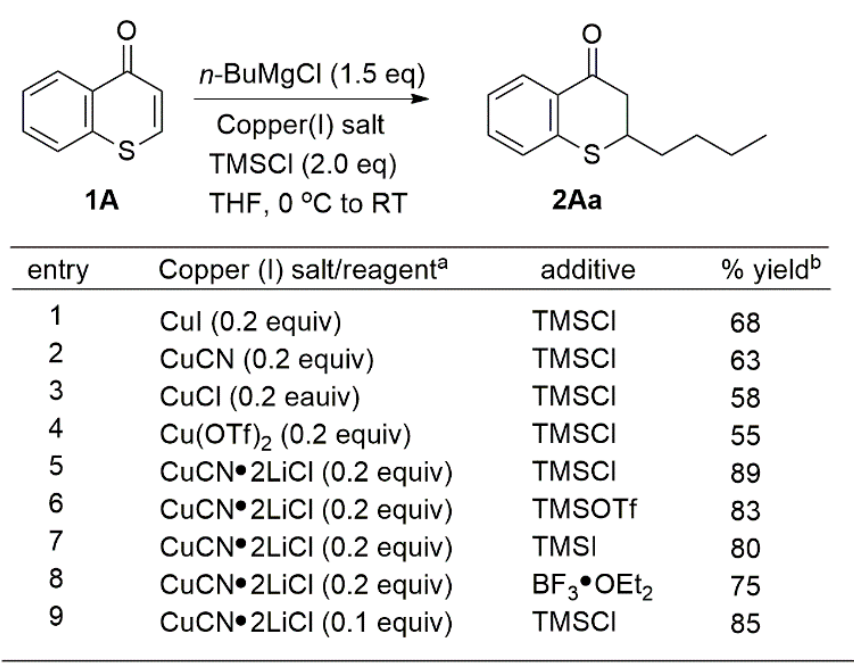

Scheme 1. Optimization of 1,4-conjugate addition of $n$-butyl magnesium chloride to thiochromone. a. Reagents were prepared by adding $n$ - $\mathrm{BuMgCl}$ to copper salts in THF. b. Yields are based on isolated products by column chromatography.

With the optimal reaction condition in hand, the scope of the Grignard reagents was explored (Scheme 2, 64-90\%). It was found that a broad range of Grignard reagents underwent conjugate addition to thiochromone $\mathbf{1 A}$ to afford 1,4-adducts $\mathbf{2 A a - A h}$ and $\mathbf{3 A a}-\mathbf{A i}$ with good reaction yields (Scheme 2). Simple Grignard reagents, such as methyl, ethyl, n-butyl, and n-hexyl Grignard reagents, were added to 1A smoothly to afford 1,4-adducts with excellent efficiency (Scheme 2, 75-88\%). Steric bulkier Grignard reagents, such as $i$-Pr, $t$-butyl Grignard reagents, gave lower yields (Scheme 2, 2Ae, $69 \%$ and 2Af, 64\%). Cyclic Grignard reagents were also tolerated to give good yields of 1,4-adducts (Scheme 2, 2Ag, 82\% and 2Ah, 85\%). Aromatic Grignard reagents also reacted very well under these optimal reaction conditions. PhMgBr was added to thiochromone 1A to offer 1,4-adduct 3Aa in an $89 \%$ yield. Grignard reagents with electron-donating groups on the aromatic ring were also found to work well (Scheme 2, 3Ab-Ad, 80-90\%). Grignard reagents with strong electron-withdrawing groups on the aromatic ring were also tolerated (Scheme 2, 3Ae, 70\%). Grignard reagents prepared from extended aryl bromides, such as 2-bromonaphthalene and 9-bromophenanthrene, were also added to thiochromone 1A smoothly with high yields (Scheme 2, 3Af, 84\%; 3Ag, 78\%). To our delight, Grignard reagents prepared from aromatic heterocycles also worked well. Both (2-furyl)magnesium bromide and 2-thienylmagnesium bromide were added to thiochromone 1A to afford corresponding 1,4-adducts in good yields (Scheme 2, 3Ah, 79\%; 3Ai, 75\%). 


\begin{tabular}{|c|c|c|c|}
\hline entries $^{a}$ & $R^{b}$ & Product & yield $^{c}$ \\
\hline 1 & $n-\mathrm{Bu}$ & $2 \mathrm{Aa}$ & $88 \%$ \\
\hline 2 & $\mathrm{Me}$ & $2 A b$ & $75 \%$ \\
\hline 3 & Et & $2 A c$ & $79 \%$ \\
\hline 4 & Hexyl & 2Ad & $86 \%$ \\
\hline 5 & $i-\operatorname{Pr}$ & $2 \mathrm{Ae}$ & $69 \%$ \\
\hline 6 & $t$-Bu & $2 A f$ & $64 \%$ \\
\hline 7 & cyclopropyl & $2 \mathrm{Ag}$ & $82 \%$ \\
\hline 8 & cyclohexyl & $2 \mathrm{Ah}$ & $85 \%$ \\
\hline 9 & $\mathrm{C}_{6} \mathrm{H}_{5}$ & $3 A a$ & $89 \%$ \\
\hline 10 & 2- $\mathrm{MeC}_{6} \mathrm{H}_{4}$ & $3 A b$ & $80 \%$ \\
\hline 11 & 4- $\mathrm{MeOC}_{6} \mathrm{H}_{4}$ & $3 \mathrm{Ac}$ & $90 \%$ \\
\hline 12 & $2-\mathrm{MeOC}_{6} \mathrm{H}_{4}$ & 3Ad & $83 \%$ \\
\hline 13 & $3,5-\left(\mathrm{CF}_{3}\right)_{2} \mathrm{C}_{6} \mathrm{H}_{3}$ & $3 \mathrm{Ae}$ & $70 \%$ \\
\hline 14 & 2-Naphthyl & 3Af & $84 \%$ \\
\hline 15 & 9-phenanthryl & $3 \mathrm{Ag}$ & $78 \%$ \\
\hline 16 & furyl & $3 A h$ & $79 \%$ \\
\hline 17 & thienyl & $3 A \mathrm{i}$ & $75 \%$ \\
\hline
\end{tabular}

Scheme 2. The scope of Grignard reagents in conjugate addition to thiochromone. a. All the reactions were performed using 1.5 equiv of $\mathrm{RMgX}$ in the presence of 2.0 equiv of TMSCI unless noted otherwise. b. RMgX were commercially available or prepared from corresponding RX in THF and used as a THF solution. c. Yields are based on isolated products by column chromatography.

With the optimal reaction addition for conjugate addition to thiochromone $\mathbf{1 A}$ in hand, we next investigated the scope of thiochromone substrates for the conjugate addition of Grignard reagents. A number of substituted thiochromones 1B-10 were investigated. It was found that $n$-butylmagnesium chloride readily added to the substituted thiochromones $\mathbf{1 B}-\mathbf{1 O}$ to afford 1,4-adducts $\mathbf{2 B a - 2 O a}$ with good yields (Scheme 3, 73-86\%). Thiochromones bearing simple alkyl groups, such as a methyl group, reacted with $n$-BuMgCl to afford 2Ba-2Da in good yields under the optimal reaction condition (Scheme 3,80-84\%). The bulky $t$-butyl group was also tolerated to afford 1,4-adduct 2Ea with good yield. Thiochromones with halides, such as $\mathrm{F}, \mathrm{Br}$, and $\mathrm{Cl}$, also reacted smoothly with $n$-BuMgCl (Scheme 3, 74-80\%). Thiochromones with two halides on the aromatic ring, such as 6,8-difluorothiochromanone and 6,8-dichlorothiochromone, were also tolerated (Scheme 3, 2Ka, 73\% and $\mathbf{2 L a}, 77 \%$ ). Electron-donating groups, such as MeO-, also worked well to afford 1,4-adduct $2 \mathrm{Ma}$ and $\mathbf{2 N a}$ in higher yields (Scheme 3). Thiochromane $\mathbf{1 0}$ with an extended aromatic structure also underwent conjugate addition with $n$-BuMgCl to afford 1,4-adduct 2Oa in a 77\% yield (Scheme 3). 


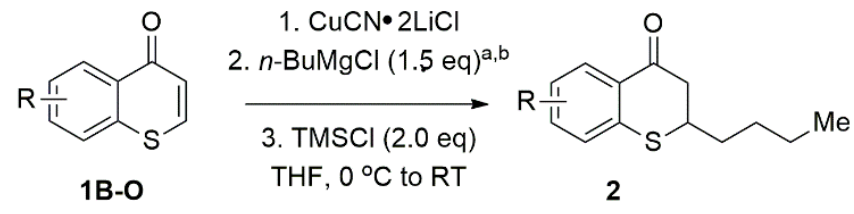<smiles>CCCCC1CC(=O)c2cc(C)ccc2S1</smiles><smiles>CCCCC1CC(=O)c2cc(C)c(C)cc2S1</smiles><smiles>CCCCC1CC(=O)c2cccc([N+](=O)[O-])c2S1</smiles>

2Ba, $83 \%^{\mathrm{c}}$

$2 \mathrm{Ca}, 84 \%^{\circ}$

2Da, $80 \%^{\mathrm{c}}$<smiles>CCCCC1CC(=O)c2cc(C(C)(C)C)ccc2S1</smiles><smiles>CCCCC1CC(=O)c2cc(Cl)ccc2S1</smiles><smiles>CCCCC1CC(=O)c2cc(Br)ccc2S1</smiles>

2Ea, $75 \%^{\mathrm{c}}$

2Ga, $80 \%^{\circ}$

$2 \mathrm{Ha}, 79 \%^{\mathrm{c}}$<smiles>CCCCC1CC(=O)c2cc(F)ccc2S1</smiles><smiles>CCCCC1CC(=O)c2cc(F)cc(F)c2S1</smiles>

2Ka, $73 \%$ c<smiles>CCCCC1CC(=O)c2cc(Cl)cc(Cl)c2S1</smiles>

2la, $74 \%^{\mathrm{c}}$<smiles>CCCCC1CC(=O)c2cc(OC)ccc2S1</smiles><smiles>CCCCC1CC(=O)c2cc3ccc(CCCC4CC(=O)c5cc(OC)c(OC)cc5S4)cc3cc2S1</smiles>

2Ma, $86 \%^{\circ}$

$2 \mathrm{Na}, 85 \%^{\mathrm{C}}$

20a, $77 \%^{\mathrm{c}}$

Scheme 3. Scope of the substituted thiochromones with $n$-BuMgCl. a. All the reactions were performed using 1.5 equiv of $\mathrm{BuMgCl}$ in the presence of 2.0 equiv of TMSCI unless noted otherwise. $\mathrm{b}$. $\mathrm{RMgX}$ were commercially available or prepared from corresponding RX in THF and used as a THF solution. c. Yields are based on isolated products by column chromatography.

The scope of thiochromones was also explored with $\mathrm{PhMgBr}$ to synthesize various thioflavanones. Phenylmagnesium bromide underwent conjugate addition to thiochromones 1B-1P smoothly to furnish thioflavanones with good yields (Scheme 4). It was found that thiochromones with simple alkyl groups, such as methyl, on the aromatic ring reacted smoothly with $\mathrm{PhMgBr}$ to afford 1,4-adduct in good yields (Scheme 4, 83-88\%). Bulky groups (i-Pr) were also tolerated (Scheme 4, 3Ea, 77\%). PhMgBr also underwent conjugate addition to thiochromones with halides $\mathrm{F}, \mathrm{Br}$, and $\mathrm{Cl}$ on the aromatic ring with high efficiency (Scheme 4, 78-82\%). Thiochromones with two halides on the aromatic ring, such as 6,8-diflurothiochromanone and 6,8-dichlorothiochromone, were also tolerated to afford good yields of 1,4-adduct (Scheme 4, 3Ka, 70\% and 3La, 76\%). Electron-donating groups, such as MeO-, were also tolerated to furnish 1,4-adducts in an excellent yield (Scheme 4, 3Ma, $84 \%$ and $3 \mathbf{N a}, 83 \%$ ). The steric hindrance was not a problem as $\mathrm{PhMgBr}$ adds to 8-substituted thiochromone (8-MeO-, 8-i-Pr) with high yields (Scheme 4). PhMgBr also underwent conjugate addition to thiochromones with extended aromatic structures with high efficiency (Scheme 4, 30a, 81\%; 3Pa, 80\%). 
<smiles>O=c1ccsc2cc[R][c-]c12</smiles>

1B-P
1. $\mathrm{CuCN} \bullet 2 \mathrm{LiCl}$

2. $\mathrm{PhMgBr}(1.5 . \mathrm{eq})^{\mathrm{a}, \mathrm{b}}$

3. TMSCl (2.0 eq) THF, $0^{\circ} \mathrm{C}$ to RT<smiles>O=C1CC(c2ccccc2)Sc2cc[R1]cc21</smiles><smiles>Cc1ccc2c(c1)C(=O)CC(c1ccccc1)S2</smiles>

3Ba, $86 \%^{\mathrm{C}}$<smiles>CCCc1cccc2c1SC(c1ccccc1)CC2=O</smiles>

3Ea, $77 \%^{\mathrm{C}}$<smiles>O=C1CC(c2ccccc2)Sc2ccc(Br)cc21</smiles>

$3 \mathrm{Ha}, 80 \%^{\mathrm{c}}$<smiles>O=C1CC(c2ccccc2)Sc2c(F)cc(F)cc21</smiles>

3Ka, $70 \%^{\mathrm{c}}$<smiles>Cc1cc2c(cc1C)C(=O)CC(c1ccccc1)S2</smiles>

$3 \mathrm{Ca}, 88 \%^{\mathrm{c}}$<smiles>Cc1cccc2c1SC(c1ccccc1)CC2=O</smiles>

3Da, $83 \%^{\mathrm{c}}$<smiles>Cc1cc(C)c2c(c1)C(=O)CC(c1ccccc1)S2</smiles>

3Fa, $85 \%^{\mathrm{c}}$<smiles>O=C1CC(c2ccccc2)Sc2ccc(Cl)cc21</smiles>

$3 \mathrm{Ga}, 82 \%^{\circ}$<smiles>O=C1CC(c2ccccc2)Sc2ccc(F)cc21</smiles>

3la, $78 \%^{c}$<smiles>O=C1CC(c2ccccc2)Sc2ccc(C(F)(F)F)cc21</smiles>

3Ja, $75 \%^{\mathrm{C}}$<smiles>O=C1CC(c2ccccc2)Sc2c(Cl)cc(Cl)cc21</smiles>

3La, $76 \%{ }^{\mathrm{c}}$<smiles>COc1cccc2c1SC(c1ccccc1)CC2=O</smiles>

$3 \mathrm{Ma}, 84 \%^{\mathrm{c}}$<smiles>COc1cc2c(cc1OC)C(=O)CC(c1ccccc1)S2</smiles>

$3 \mathrm{Na}, 83 \%^{\mathrm{c}}$<smiles>O=C1CC(c2ccccc2)Sc2cc3ccccc3cc21</smiles>

$30 a, 81 \%^{c}$<smiles>O=C1CC(c2ccccc2)Sc2c1ccc1ccccc21</smiles>

$3 \mathrm{~Pa}, 80 \%^{\mathrm{C}}$

Scheme 4. Reactions of $\mathrm{PhMgBr}$ with substituted thiochromones. a. All the reactions were performed using 1.5 equiv of $\mathrm{PhMgBr}$ in the presence of 2.0 equiv of TMSCI unless noted otherwise. $\mathrm{b}$. PhMgBr were commercially available. c. Yields are based on isolated products by column chromatography.

Thiochromanones, i.e., thiochroman-4-ones, 2-alkyltiochroman-4-ones, and thioflavanones (2-arylthioflavanones), are valuable synthons and vital precursors in organic synthesis for bioactive thiochromanone derivatives. [31-38] In our previous investigation, 2-alkylthiochroman-4-ones were successfully converted into other useful thiochroman-4-one derivatives for additional synthetic application [66]. The 1,4-adducts-thioflavones can also be utilized for further synthetic applications towards 2-aryl substituted thiochroman-4-one derivatives (Scheme 5). For example, thioflavanone 3 was 
converted to chlorinated thiochromone 4 upon treatment with excess $N$-chlorosuccinimide and pyridine (Scheme 5, 4Aa, 65\%; 4Af, 68\%). It was also oxidized to sulfone 5 with excess $m$-chloroperobenzoic acid (m-CPBA) in dichloromethane (Scheme 5, 5Ac, 74\%; 5Ae, 70\%). After treatment with $\mathrm{N}$-chlorosuccinimide (NCS, 1.0 equivalent), thioflavanone 3 was transformed to thiochromone 6 with good yields (Scheme 5, 6Aa, 70\%; 6Af, 66\%). It was also reduced by sodium borohydride to the corresponding alcohol 7 (Scheme 3, 7Aa, 81\%; 7Ab, 85\%).
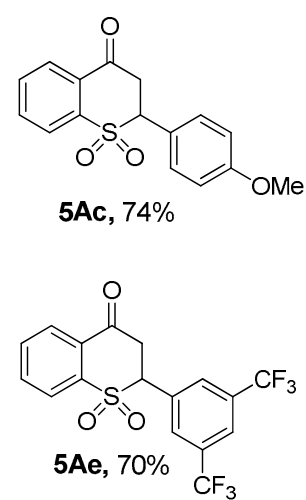<smiles>CC(C)(C)OC(=O)c1ccccc1-c1sc2ccccc2c(=O)c1Cl</smiles><smiles>CC(C)(C)O[Na]</smiles>

4Aa, $65 \%$
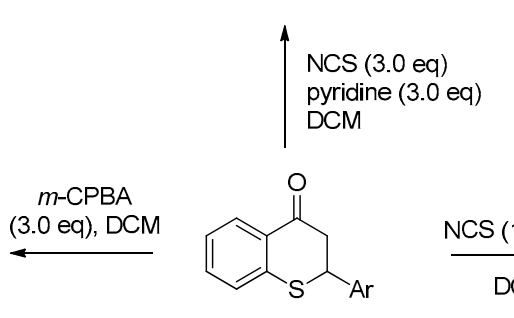

3

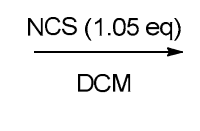

6Aa, $70 \%$

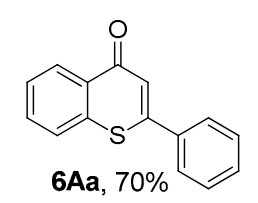<smiles>O=c1cc(-c2ccc3ccccc3c2)sc2ccccc12</smiles>

6Af, $66 \%$<smiles>OC1Cc2ccccc2S1</smiles>

7 Aa, $81 \%$

$$
\begin{aligned}
& \mathrm{NaBH}_{4} \\
& \mathrm{EtOH}
\end{aligned}
$$<smiles>Cc1ccccc1C1CC(O)c2ccccc2S1</smiles>

7Ab, $85 \%$

Scheme 5. Synthetic applications of thioflavanones.

\section{Materials and Methods}

\subsection{General Methods}

The ${ }^{1} \mathrm{H},{ }^{13} \mathrm{C}$, and ${ }^{19} \mathrm{~F}-\mathrm{NMR}$ spectra were recorded on a BRUKER Ascend ${ }^{\mathrm{TM}} 400 \mathrm{NMR}$ spectrometer (Bruker Corporation, Billerica, MA, USA), operating at $400 \mathrm{MHz}$ for ${ }^{1} \mathrm{H}$ and $100 \mathrm{MHz}$ for ${ }^{13} \mathrm{C}$ and $376 \mathrm{MHz}$ for ${ }^{19} \mathrm{~F}$. Samples for NMR spectra were dissolved in deuterated chloroform unless otherwise noted. Analytical thin layer chromatography (TLC) was performed on silica gel plates, 60 mesh, with an $\mathrm{F}_{254}$ indicator. Visualization was accomplished by UV light $(254 \mathrm{~nm})$, and/or a $10 \%$ ethanol solution of phosphomolybdic acid and/or $\mathrm{KMnO}_{4}$ stain prepared by dissolving $1.5 \mathrm{~g} \mathrm{KMnO}$, 10 g potassium carbonate, and $1.25 \mathrm{~mL}$ of $10 \%$ sodium hydroxide in $200 \mathrm{~mL}$ of water. Flash chromatography was performed with 230-400 mesh silica gel. Infrared (IR) spectra were recorded on a Nicolet iS10 FT-IR spectrometer (Thermo Scientific, Waltham, MA, USA) as neat samples (thin films).

\subsection{Materials}

Solvents and chemicals were obtained from commercial sources and used without further purification unless stated otherwise. Anhydrous tetrahydrofuran (THF) was purchased from Sigma Aldrich (Sigma-Aldrich, St. Louis, MO, USA). TMSCl was distilled from $\mathrm{CaH}_{2}$ under a positive $\mathrm{N}_{2}$ atmosphere. Grignard reagents were purchased from Sigma Aldrich or prepared from the corresponding bromocompounds. All glassware was flamed-dried under high vacuum and purged with argon to cool to room temperature. Low-temperature baths were prepared using dry ice-isopropanol slush 
bath mixtures. All 1,4-conjugate addition reactions with Grignard reagents were conducted under a positive dry argon atmosphere in anhydrous solvents in flasks fitted with a rubber septum.

3.3. General Procedure A: Conjugate Addition Reactions of Grignard Reagents ( $\mathrm{RMgX}$ or $\mathrm{ArMgX} ; \mathrm{X}=\mathrm{Cl}$ or $\mathrm{Br})$ to Thiochromones Catalyzed by $\mathrm{CuCN} \cdot 2 \mathrm{LiCl}(0.2 \mathrm{eq})$

To flame-dried $\mathrm{LiCl}$ ( $8.5 \mathrm{mg}, 0.2 \mathrm{mmol}, 0.4$ equivalent) under argon, $\mathrm{CuCN}(9.0 \mathrm{mg}, 0.1 \mathrm{mmol}$, 0.2 equivalent) and THF $(1.0 \mathrm{~mL})$ were added. The resultant mixture was stirred for $10 \mathrm{~min}$ at room temperature and then cooled to $0{ }^{\circ} \mathrm{C}$ followed by the addition of a Grignard reagent $(0.75 \mathrm{mmol}, 1.5$ equivalent). The resultant solution was stirred for an additional $30 \mathrm{~min}$ at $0{ }^{\circ} \mathrm{C}$ under argon and then thiochromones [0.5 mmol mixed with TMSCl $(1.0 \mathrm{mmol})$ in THF $1.0 \mathrm{~mL})]$ were added. The reaction mixture was allowed to warm up to room temperature during overnight stirring. Then, the reaction mixture was quenched with saturated aqueous $\mathrm{NH}_{4} \mathrm{Cl}(10.0 \mathrm{~mL})$ and extracted with ethyl acetate $(3 \times 10.0 \mathrm{~mL})$. The combined organic phase was washed with brine $(15.0 \mathrm{~mL})$, dried over anhydrous $\mathrm{Na}_{2} \mathrm{SO}_{4}$, filtered, concentrated in vacuo, and purified by flash column chromatography (silica gel, $0-2 \%$ ethyl acetate in hexane, $v / v$ ) to give pure compounds.

\subsection{Synthesis}

HRMS data for compounds $2 \mathrm{Ag}$, 3Ag, 2Ka, 2La, 2Na, 3Ea, 3Fa, 3Ka-3Ma, 3Pa, 4Af, 5Ac, 5Ae, and $7 \mathrm{Ab}$ were analyzed by TOF MS. Compounds 2Aa-2Af [66], 2Ah [65], 2Ba-2Ia [66], 2Ma [66], 2Oa [66], 3Aa-3Af [51,67], 3Ah-3Ai [51,59], 3Ba-3Da [51,67], 3Ga-3Ja [51,67], 3Ma [51], 3Na[58], 3Oa [51,67], 4Aa [68], 6Aa [69], 6Af [70], and 7Aa [59] have been fully characterized and reported. (Supplementary materials)

\subsubsection{Synthesis of 2-Cyclopropylthiochroman-4-one (2Ag)}

Employing General Procedure A, using cyclopropylmagnesium bromide (1.0 M, 1.0 mL, $1.0 \mathrm{mmol})$ and thiochromone $(81 \mathrm{mg}, 0.5 \mathrm{mmol})$, after purification by flash column chromatography (silica gel, 0-2\% ethyl acetate: hexanes, $v / v)$, gave a light-yellow solid $2 \mathrm{Ag}(84 \mathrm{mg}, 82 \%): \mathrm{mp} 83-84{ }^{\circ} \mathrm{C}$; IR (neat) $3056(\mathrm{w}), 3001(\mathrm{w}), 2921(\mathrm{w}), 1671(\mathrm{~s}), 1590(\mathrm{~s}), 1456(\mathrm{w}), 1434(\mathrm{~s}), 1394(\mathrm{w}), 1284(\mathrm{~s}), 1229(\mathrm{~m}), 1154(\mathrm{w})$, $1068(\mathrm{w}), 1023(\mathrm{w}), 954(\mathrm{w}), 759(\mathrm{~s}) \mathrm{cm}^{-1},{ }^{1} \mathrm{H}$ NMR $\left(400 \mathrm{MHz}, \mathrm{CDCl}_{3}\right) \delta 0.22-0.29(\mathrm{~m}, 1 \mathrm{H}), 0.29-0.35(\mathrm{~m}$, $1 \mathrm{H}), 0.55-0.65(\mathrm{~m}, 2 \mathrm{H}), 0.95-1.07(\mathrm{~m}, 1 \mathrm{H}), 2.70(\mathrm{ddd}, J=2.80,9.60,11.6 \mathrm{~Hz}, 1 \mathrm{H}), 2.88(\mathrm{dd}, J=11.6$, $16.4 \mathrm{~Hz}, 1 \mathrm{H}), 3.08(\mathrm{dd}, J=2.8,16.4 \mathrm{~Hz}, 1 \mathrm{H}), 7.09(\mathrm{ddd}, J=1.2,7.2,8.0 \mathrm{~Hz}, 1 \mathrm{H}), 7.20(\mathrm{ddd}, J=0.4,1.2$, $8.0 \mathrm{~Hz}, 1 \mathrm{H}), 7.31(\mathrm{ddd}, J=1.6,7.2,8.0 \mathrm{~Hz}, 1 \mathrm{H}), 8.01(\mathrm{ddd}, J=0.4,1.6,8.0 \mathrm{~Hz}, 1 \mathrm{H}) ;{ }^{13} \mathrm{C} \mathrm{NMR}(100 \mathrm{MHz}$, $\left.\mathrm{CDCl}_{3}\right) \delta 4.7,5.0,15.4,46.4,47.2,124.8,127.5,129.0,130.6,133.5,142.1,194.7$; HRMS (EI-ion trap) $\mathrm{m} / z$ : $[\mathrm{M}+1]^{+}$calcd for $\mathrm{C}_{12} \mathrm{H}_{13} \mathrm{OS}$, 205.0687; found 205.0679.

\subsubsection{Synthesis of 2-(9-Phenanthryl)thiochroman-4-one (3Ag)}

Employing General Procedure A, using 9-phenanthrenylmagnesium bromide (1.0 M, 1.0 mL, $1.0 \mathrm{mmol})$ and thiochromone $(81 \mathrm{mg}, 0.50 \mathrm{mmol})$, after purification by flash column chromatography (silica gel, $0-2 \%$ ethyl acetate: hexanes, $v / v)$, gave a yellow solid $3 \mathrm{Ag}(133 \mathrm{mg}, 78 \%)$ : $\mathrm{mp} 180-181^{\circ} \mathrm{C}$; IR (neat) $3062(\mathrm{w}), 2922(\mathrm{w}), 1668(\mathrm{~s}), 1582(\mathrm{~m}), 1450(\mathrm{w}), 1439(\mathrm{w}), 1295(\mathrm{~m}), 1089(\mathrm{w}), 892(\mathrm{w}), 760(\mathrm{w})$, $746(\mathrm{~m}), 722(\mathrm{~m}) \mathrm{cm}^{-1} ;{ }^{1} \mathrm{H}$ NMR $\left(400 \mathrm{MHz}, \mathrm{CDCl}_{3}\right) \delta 3.38(\mathrm{dd}, J=2.8,16.4 \mathrm{~Hz}, 1 \mathrm{H}), 3.56(\mathrm{dd}, J=12.8$, $16.4 \mathrm{~Hz}, 1 \mathrm{H}), 5.44(\mathrm{dd}, J=2.8,12.8 \mathrm{~Hz}, 1 \mathrm{H}), 7.19(\mathrm{ddd}, J=1.2,7.2,8.0 \mathrm{~Hz}, 1 \mathrm{H}), 7.37(\mathrm{ddd}, J=1.2,7.2$, $8.0 \mathrm{~Hz}, 1 \mathrm{H}), 7.54(\mathrm{ddd}, J=0.8,7.2,8.0 \mathrm{~Hz}, 1 \mathrm{H}), 7.57-7.65(\mathrm{~m}, 3 \mathrm{H}), 7.80-7.85(\mathrm{~m}, 2 \mathrm{H}), 8.13-8.19(\mathrm{~m}, 2 \mathrm{H})$, $8.60(\mathrm{~d}, J=8.0 \mathrm{~Hz}, 1 \mathrm{H}), 8.69(\mathrm{dd}, J=1.2,8.0 \mathrm{~Hz}, 1 \mathrm{H}) ;{ }^{13} \mathrm{C} \mathrm{NMR}\left(100 \mathrm{MHz}, \mathrm{CDCl}_{3}\right) \delta 41.2,46.2,122.5$, 123.6, 123.7, 125.4, 126.0, 126.9, 127.1, 127.4, 127.5, 129.0, 129.4, 129.5, 130.3, 130.5, 131.0, 131.04, 132.3, 133.7, 142.2, 194.9; HRMS (EI-ion trap) $m / z$ : $[\mathrm{M}+1]^{+}$calcd for $\mathrm{C}_{23} \mathrm{H}_{17} \mathrm{OS}, 341.1000$; found 341.1014 .

\subsubsection{Synthesis of 6,8-Difluoro-2-n-butylthiochroman-4-one (2Ka)}

Employing General Procedure A, using $n$-butylmagnesium chloride ( $1.71 \mathrm{M}, 0.44 \mathrm{~mL}, 0.75 \mathrm{mmol})$ and thiochromone $(99 \mathrm{mg}, 0.50 \mathrm{mmol})$, after purification by flash column chromatography (silica gel, 
0-2\% ethyl acetate: hexanes, v/v), gave a light-yellow oil 2Ka (93 mg, 73\%): IR (neat) 3083 (w), 2958 (s), 2929 (s), 2858 (s), 1686 (s), $1611(\mathrm{~m}), 1571(\mathrm{~m}), 1437(\mathrm{~m}), 1571(\mathrm{~m}), 1437$ (s), 1326 (s), 1281 (s), 1217 (w), $1112(\mathrm{~m}), 997(\mathrm{~m}) 878(\mathrm{w}), 856(\mathrm{w}), 641(\mathrm{w}), 620(\mathrm{~m}) \mathrm{cm}^{-1} ;{ }^{1} \mathrm{H} \mathrm{NMR}\left(400 \mathrm{MHz}, \mathrm{CDCl}_{3}\right) \delta 0.85(\mathrm{t}$, $J=7.2 \mathrm{~Hz}, 3 \mathrm{H}), 1.22-1.33(\mathrm{~m}, 2 \mathrm{H}), 1.34-1.47(\mathrm{~m}, 2 \mathrm{H}), 1.67(\mathrm{q}, J=7.8 \mathrm{~Hz}, 2 \mathrm{H}), 2.75(\mathrm{dd}, J=11.2,16.4 \mathrm{~Hz}$, $1 \mathrm{H}), 2.99(\mathrm{dd}, J=2.8,16.4 \mathrm{~Hz}, 1 \mathrm{H}), 3.36-3.46(\mathrm{~m}, 1 \mathrm{H}), 6.93(\mathrm{ddd}, J=2.8,8.0,9.2 \mathrm{~Hz}, 1 \mathrm{H}), 7.57(\mathrm{ddd}$, $J=1.2,2.8,8.8 \mathrm{~Hz}, 1 \mathrm{H}) ;{ }^{13} \mathrm{C} \mathrm{NMR}\left(100 \mathrm{MHz} \mathrm{CDCl}_{3}\right) \delta 13.9,22.3,28.7,34.1,41.1,45.9,108.7(\mathrm{t}, J=26 \mathrm{~Hz})$, $110.9(\mathrm{dd}, J=3.0,22 \mathrm{~Hz}), 125.4(\mathrm{dd}, J=3.0,18 \mathrm{~Hz}), 132.6(\mathrm{dd}, J=3.0,7.0 \mathrm{~Hz}), 158.6(\mathrm{dd}, J=11,246 \mathrm{~Hz})$, $159.7(\mathrm{dd}, J=11,246 \mathrm{~Hz}), 192.6 ;{ }^{19} \mathrm{~F}$ NMR $\left(376 \mathrm{MHz}, \mathrm{CDCl}_{3}\right) \delta-107.4(\mathrm{dd}, J=6.4,8.7 \mathrm{~Hz}),-114.1(\mathrm{dt}$, $J=6.3,8.3 \mathrm{~Hz}$ ); HRMS (EI-ion trap) $m / z$ : $[\mathrm{M}+\mathrm{Na}]^{+}$calcd for $\mathrm{C}_{13} \mathrm{H}_{14} \mathrm{ONaSF}_{2}, 279.0631$; found 279.0642 .

\subsubsection{Synthesis of 6,8-Dichloro-2-n-butylthiochroman-4-one (2La)}

Employing General Procedure A, using n-butylmagnesium chloride (1.71 M, $0.32 \mathrm{~mL}, 0.54 \mathrm{mmol})$ and thiochromone $(83 \mathrm{mg}, 0.36 \mathrm{mmol}$ ), after purification by flash column chromatography (silica gel, 0-2\% ethyl acetate: hexanes, $v / v)$, gave a light-yellow oil 2La (80 mg,77\%): IR (neat) $3067(\mathrm{w}), 2956(\mathrm{~m})$, 2928 (m), 2858 (m), 1686 (s), 1571 (m), 1538 (w), 1465 (w), 1426 (w), 1397 (s), 1285 (w), $1244(\mathrm{~m}), 1120$ (w), $1053(\mathrm{w}), 873(\mathrm{w}), 812(\mathrm{~m}) \mathrm{cm}^{-1},{ }^{1} \mathrm{H}$ NMR $\left(400 \mathrm{MHz}, \mathrm{CDCl}_{3}\right) \delta 0.85(\mathrm{t}, J=7.2 \mathrm{~Hz}, 3 \mathrm{H}), 1.23-1.33$ $(\mathrm{m}, 2 \mathrm{H}), 1.35-1.46(\mathrm{~m}, 2 \mathrm{H}), 1.68(\mathrm{q}, J=7.2 \mathrm{~Hz}, 2 \mathrm{H}), 2.72(\mathrm{dd}, J=11.2,16.4 \mathrm{~Hz}, 1 \mathrm{H}), 2.96(\mathrm{dd}, J=3.2$, $16.4 \mathrm{~Hz}, 1 \mathrm{H}), 3.34-3.43(\mathrm{~m}, 1 \mathrm{H}), 7.43(\mathrm{~d}, J=2.4 \mathrm{~Hz}, 1 \mathrm{H}), 7.93(\mathrm{~d}, J=2.4 \mathrm{~Hz}, 1 \mathrm{H}) ;{ }^{13} \mathrm{C} \mathrm{NMR}(100 \mathrm{MHz}$, $\left.\mathrm{CDCl}_{3}\right) \delta 13.9,22.3,28.6,34.1,40.8,44.8,127.2,130.6,132.4,132.7,133.5,139.7,192.9$; HRMS (EI-ion trap) $m / z:[\mathrm{M}-1]^{+}$calcd for $\mathrm{C}_{13} \mathrm{H}_{13} \mathrm{OSCl}_{2}, 287.0064$; found 287.0067 .

\subsubsection{Synthesis of 6,7-Dimethoxyl-2-n-butylthiochroman-4-one (2Na)}

Employing General Procedure A, using n-butylmagnesium chloride (1.71 M, $0.27 \mathrm{~mL}, 0.47 \mathrm{mmol})$ and thiochromone $(69 \mathrm{mg}, 0.31 \mathrm{mmol})$, after purification by flash column chromatography (silica gel, 0-2\% ethyl acetate: hexanes, $v / v)$, gave a light-yellow oil 2Na (74 mg, 85\%): IR (neat) $3077(\mathrm{w}), 3000(\mathrm{w})$, 2954 (s), 2927 (s), 2853 (s), 1660 (s), 1591 (s), 1498 (s), 1462 (m), 1436 (m), 1388 (s), 1352 (m), 1258 (s), 1210 (s), $1177(\mathrm{~m}), 1146(\mathrm{~m}), 1098$ (w), 1033 (s), $872(\mathrm{w}), 796(\mathrm{w}) \mathrm{cm}^{-1},{ }^{1} \mathrm{H} \mathrm{NMR}\left(400 \mathrm{MHz}, \mathrm{CDCl}_{3}\right) \delta 0.84(\mathrm{t}$, $\mathrm{J}=7.2 \mathrm{~Hz}, 3 \mathrm{H}), 1.22-1.31(\mathrm{~m}, 2 \mathrm{H}), 1.32-1.43(\mathrm{~m}, 2 \mathrm{H}), 1.64(\mathrm{q}, J=7.2 \mathrm{~Hz}, 2 \mathrm{H}), 2.66(\mathrm{dd}, J=11.2,16.4 \mathrm{~Hz}$, $1 \mathrm{H}), 2.92(\mathrm{dd}, J=3.2,16.4 \mathrm{~Hz}, 1 \mathrm{H}), 3.35-3.46(\mathrm{~m}, 1 \mathrm{H}), 3.82(\mathrm{~s}, 3 \mathrm{H}), 3.84(\mathrm{~s}, 3 \mathrm{H}), 6.61(\mathrm{~s}, 1 \mathrm{H}), 7.51(\mathrm{~s}, 1 \mathrm{H})$; ${ }^{13} \mathrm{C}$ NMR $\left(100 \mathrm{MHz} \mathrm{CDCl}_{3}\right) \delta 13.9,22.3,28.9,34.1,42.3,46.0,56.0,56.2,109.0,110.2,123.9,135.6,147.1$, 153.8, 193.6; HRMS (EI-ion trap) $m / z$ : $[\mathrm{M}+1]^{+}$calcd for $\mathrm{C}_{15} \mathrm{H}_{21} \mathrm{O}_{3} \mathrm{~S}, 281.1211$; found 281.1210.

\subsubsection{Synthesis of 6-Isopropyl-2-phenylthiochroman-4-one (3Ea)}

Employing General Procedure A, using phenylmagnesium bromide (2.8 M, 0.25 mL, $0.71 \mathrm{mmol})$ and thiochromone (95 mg, $0.47 \mathrm{mmol}$ ), after purification by flash column chromatography (silica gel, 0-2\% ethyl acetate: hexanes, $v / v)$, gave a yellow solid 3Ea (102 mg, 77\%): mp 78-79 ${ }^{\circ} \mathrm{C}$; IR (neat) 3056 (w), 2965 (s), $2927(\mathrm{~m}), 1673$ (s), $1576(\mathrm{~m}), 1489(\mathrm{w}), 1451(\mathrm{w}), 1411(\mathrm{~m}), 1286(\mathrm{w}), 1262(\mathrm{~s}), 1147(\mathrm{w}), 1973$ $(\mathrm{w}), 1042(\mathrm{w}), 780(\mathrm{w}), 766(\mathrm{w}), 731(\mathrm{w}), 698(\mathrm{w}) \mathrm{cm}^{-1} ;{ }^{1} \mathrm{H} \mathrm{NMR}\left(400 \mathrm{MHz}, \mathrm{CDCl}_{3}\right) \delta 1.24(\mathrm{~d}, J=6.8$ $\mathrm{Hz}, 3 \mathrm{H}), 1.31(\mathrm{~d}, J=6.8 \mathrm{~Hz}, 3 \mathrm{H}), 3.23(\mathrm{dd}, J=2.8,16.4 \mathrm{~Hz}, 1 \mathrm{H}), 3.26-3.34(\mathrm{~m}, 1 \mathrm{H}), 3.35(\mathrm{dd}, J=13.6$, $16.4 \mathrm{~Hz}, 1 \mathrm{H}), 4.66(\mathrm{dd}, J=2.8,13.6 \mathrm{~Hz}, 1 \mathrm{H}), 7.25(\mathrm{dd}, J=7.6,15.2 \mathrm{~Hz}, 1 \mathrm{H}), 7.34-7.51(\mathrm{~m}, 6 \mathrm{H}), 8.09$ (dd, $J=1.6,8.0 \mathrm{~Hz}, 1 \mathrm{H}) ;{ }^{13} \mathrm{C} \mathrm{NMR}\left(100 \mathrm{MHz} \mathrm{CDCl}_{3}\right) \delta 22.7,23.1,30.3,44.9,46.3,124.8,127.2,127.5,128.5$, $129.0,130.3,130.9,138.7,140.4,145.8,195.1$; HRMS (EI-ion trap) $m / z$ : $[\mathrm{M}+1]^{+}$calcd for $\mathrm{C}_{18} \mathrm{H}_{19} \mathrm{OS}$, 283.1157; found 283.1147 .

\subsubsection{Synthesis of 6,8-Dimethyl-2-phenylthiochroman-4-one (3Fa)}

Employing General Procedure A, using phenylmagnesium bromide (2.8 M, $0.13 \mathrm{~mL}, 0.35 \mathrm{mmol})$ and thiochromone $(42.8 \mathrm{mg}, 0.23 \mathrm{mmol})$, after purification by flash column chromatography (silica gel, 0-2\% ethyl acetate: hexanes, $v / v)$, gave a white solid $3 F a(52.5 \mathrm{mg}, 85 \%): \mathrm{mp} 123-124{ }^{\circ} \mathrm{C}$; IR (neat) 3041 (w), $2977(\mathrm{w}), 2922(\mathrm{~m}), 2852(\mathrm{w}), 1670(\mathrm{~s}), 1600(\mathrm{~m}), 1456(\mathrm{~m}), 1421(\mathrm{w}), 1371(\mathrm{w}), 1310(\mathrm{~m}), 1280(\mathrm{~m})$, $1250(\mathrm{~m}), 1125(\mathrm{w}), 871(\mathrm{~m}), 781(\mathrm{~m}), 706(\mathrm{~m}) \mathrm{cm}^{-1},{ }^{1} \mathrm{H}$ NMR $\left(400 \mathrm{MHz}, \mathrm{CDCl}_{3}\right) \delta 2.09(\mathrm{~s}, 3 \mathrm{H}), 2.14(\mathrm{~s}, 3$ 
H), $2.98(\mathrm{dd}, J=3.2,16.4 \mathrm{~Hz}, 1 \mathrm{H}), 3.11(\mathrm{dd}, J=13.2,16.4 \mathrm{~Hz}, 1 \mathrm{H}), 4.45(\mathrm{dd}, J=2.8,13.2 \mathrm{~Hz}, 1 \mathrm{H}), 6.98$ $(\mathrm{dd}, J=0.8,1.6 \mathrm{~Hz}, 1 \mathrm{H}), 7.12-7.23(\mathrm{~m}, 3 \mathrm{H}), 7.24-7.28(\mathrm{~m}, 2 \mathrm{H}), 7.68(\mathrm{dd}, J=0.8,1.6 \mathrm{~Hz}, 1 \mathrm{H}) ;{ }^{13} \mathrm{C} \mathrm{NMR}$ $\left(100 \mathrm{MHz}, \mathrm{CDCl}_{3}\right)$ \& 19.9, 20.7, 44.9, 46.3, 127.1, 127.5, 128.5, 129.0, 130.4, 134.1, 135.0, 136.1, 138.3, 138.8, 195.1; HRMS (EI-ion trap) $m / z$ : $[\mathrm{M}+1]^{+}$calcd for $\mathrm{C}_{17} \mathrm{H}_{17} \mathrm{OS}$, 269.1000; found 269.0999.

\subsubsection{Synthesis of 6,8-Difluoro-2-phenylthiochroman-4-one (3Ka)}

Employing General Procedure A, using phenylmagnesium bromide ( $2.8 \mathrm{M}, 0.16 \mathrm{~mL}, 0.44 \mathrm{mmol})$ and thiochromone ( $58 \mathrm{mg}, 0.293 \mathrm{mmol}$ ), after purification by flash column chromatography (silica gel, $0-2 \%$ ethyl acetate: hexanes, $v / v)$, gave a light-yellow solid $3 \mathrm{Ka}(57 \mathrm{mg}, 70 \%)$ : $\mathrm{mp} 70-71{ }^{\circ} \mathrm{C}$; IR (neat) $3076(\mathrm{~s}), 3031(\mathrm{w}), 2959(\mathrm{w}), 2892(\mathrm{w}), 1685(\mathrm{~s}), 1609(\mathrm{~m}), 1571(\mathrm{~m}), 1438(\mathrm{~m}), 1322(\mathrm{~m}), 1282(\mathrm{~m}), 1130$ (w), $995(\mathrm{~m}), 879(\mathrm{w}), 772(\mathrm{w}), 697(\mathrm{w}) \mathrm{cm}^{-1}$; ${ }^{1} \mathrm{H}$ NMR $\left(400 \mathrm{MHz}, \mathrm{CDCl}_{3}\right) \delta 3.01(\mathrm{dd}, J=0.4,3.2 \mathrm{~Hz}, 1$ H), $3.14(\mathrm{dd}, J=13.2,16.4 \mathrm{~Hz}, 1 \mathrm{H}), 4.48(\mathrm{dd}, J=3.2,13.2 \mathrm{~Hz}, 1 \mathrm{H}), 6.83(\mathrm{ddd}, J=2.8,8.0,8.8 \mathrm{~Hz}, 1 \mathrm{H})$, 7.13-7.26 (m, 5H), $7.51(\mathrm{ddd}, J=1.6,2.8,8.8 \mathrm{~Hz}, 1 \mathrm{H}) ;{ }^{13} \mathrm{C} \mathrm{NMR}\left(100 \mathrm{MHz}, \mathrm{CDCl}_{3}\right) \delta 45.0,46.3,108.9$ $(\mathrm{dd}, J=2.5,2.6 \mathrm{~Hz}), 111.2(\mathrm{dd}, J=3,23 \mathrm{~Hz}), 125.8(\mathrm{dd}, J=4,19 \mathrm{~Hz}), 127.5,128.9,129.1,132.4(\mathrm{dd}, J=$ 3.0, 7.0 Hz), 137.7, $158.3(\mathrm{dd}, J=11,247 \mathrm{~Hz}), 159.91(\mathrm{dd}, J=11,247 \mathrm{~Hz}), 192.3(\mathrm{t}, J=3.0 \mathrm{~Hz}) ;{ }^{19} \mathrm{~F}$ NMR $\left(376 \mathrm{MHz}, \mathrm{CDCl}_{3}\right) \delta-107.2(\mathrm{dd}, J=6.8,8.3 \mathrm{~Hz}),-113.5(\mathrm{dt}, J=7.5,8.3 \mathrm{~Hz})$; HRMS (EI-ion trap) $m / z$ : $[\mathrm{M}-1]^{+}$calcd for $\mathrm{C}_{15} \mathrm{H}_{9} \mathrm{OSF}_{2}, 275.0342$; found 275.0345 .

\subsubsection{Synthesis of 6,8-Dichloro-2-phenylthiochroman-4-one (3La)}

Employing General Procedure A, using phenylmagnesium bromide ( $2.8 \mathrm{M}, 0.08 \mathrm{~mL}, 0.225 \mathrm{mmol})$ and thiochromone ( $33.6 \mathrm{mg}, 0.15 \mathrm{mmol})$, after purification by flash column chromatography (silica gel, 0-2\% ethyl acetate: hexanes, $v / v)$, gave a light-yellow solid $3 \mathrm{La}(35 \mathrm{mg}, 76 \%): \mathrm{mp} 112-113{ }^{\circ} \mathrm{C}$; IR (neat) $3067(\mathrm{w}), 2921(\mathrm{~s}), 1682(\mathrm{~s}), 1571(\mathrm{~m}), 1539(\mathrm{w}), 1453(\mathrm{w}), 1397(\mathrm{~s}), 1283(\mathrm{w}), 1241(\mathrm{~m}), 1177(\mathrm{w}), 1121(\mathrm{w})$, $1051(\mathrm{w}), 808(\mathrm{w}), 767(\mathrm{w}), 697(\mathrm{~m}) \mathrm{cm}^{-1} ;{ }^{1} \mathrm{H}$ NMR $\left(400 \mathrm{MHz}, \mathrm{CDCl}_{3}\right) \delta 3.00(\mathrm{dd}, J=3.2,16.4 \mathrm{~Hz}, 1$ H), $3.10(\mathrm{dd}, J=13.2,16.4 \mathrm{~Hz}, 1 \mathrm{H}), 4.45(\mathrm{dd}, J=3.2,13.2 \mathrm{~Hz}, 1 \mathrm{H}), 7.15-7.45(\mathrm{~m}, 5 \mathrm{H}), 7.32(\mathrm{~d}, J=2.4$ $\mathrm{Hz}, 1 \mathrm{H}), 7.86(\mathrm{~d}, J=2.4 \mathrm{~Hz}, 1 \mathrm{H}) ;{ }^{13} \mathrm{C} \mathrm{NMR}\left(100 \mathrm{MHz}, \mathrm{CDCl}_{3}\right) \delta 44.8,45.3,127.51,127.53,128.9,129.2$, 131.0, 132.1, 132.5, 133.7, 137.5, 140.0, 192.6; HRMS (EI-ion trap) $m / z:[\mathrm{M}-1]^{+}$calcd for $\mathrm{C}_{15} \mathrm{H}_{9} \mathrm{OSCl}_{2}$, 306.9751; found 306.9765 .

\subsubsection{Synthesis of 8-Methoxy-2-phenylthiochroman-4-one (3Ma)}

Employing General Procedure A, using phenylmagnesium bromide $(2.8 \mathrm{M}, 0.16 \mathrm{~mL}, 0.44 \mathrm{mmol})$ and thiochromone ( $55 \mathrm{mg}, 0.29 \mathrm{mmol}$ ), after purification by flash column chromatography (silica gel, 0-2\% ethyl acetate: hexanes, v/v), gave a light-yellow solid 3Ma (66 mg, 84\%): $\mathrm{mp} 147-148{ }^{\circ} \mathrm{C}$; IR (neat) 3017 (w), 2972 (W), 2936 (w), 1673 (s), $1579(\mathrm{~m}), 1559$ (m), 1451 (m), 1420 (m), $1316(\mathrm{~m}), 1254$ (s), 1155 (w), 1055 (w), 1031 (s), 789 (m), $770(\mathrm{~m}), 712(\mathrm{w}), 697(\mathrm{~m}) \mathrm{cm}^{-1} ;{ }^{1} \mathrm{H}$ NMR $\left(400 \mathrm{MHz}, \mathrm{CDCl}_{3}\right) \delta 3.08$ (dd, $J=2.8,16.0 \mathrm{~Hz}, 1 \mathrm{H}), 3.21(\mathrm{dd}, J=13.6,16 \mathrm{~Hz}, 1 \mathrm{H}), 3.82(\mathrm{~s}, 3 \mathrm{H}), 4.54(\mathrm{dd}, J=2.8,13.6 \mathrm{~Hz}, 1 \mathrm{H}), 6.91(\mathrm{dd}$, $J=1.2,8.0 \mathrm{~Hz}, 1 \mathrm{H}), 7.09(\mathrm{t}, J=8.0 \mathrm{~Hz}, 1 \mathrm{H}), 7.22-7.32(\mathrm{~m}, 3 \mathrm{H}), 7.33-7.38(\mathrm{~m}, 2 \mathrm{H}), 7.71(\mathrm{dd}, J=1.2,8.0 \mathrm{~Hz}$, $1 \mathrm{H}) ;{ }^{13} \mathrm{C}$ NMR $\left(100 \mathrm{MHz}, \mathrm{CDCl}_{3}\right) \delta 44.4,46.0,56.3,114.2,121.1,124.8,127.5,128.5,129.0,131.3,131.9$, 138.7, 155.1, 194.6; HRMS (EI-ion trap) $m / z$ : $[\mathrm{M}+1]^{+}$calcd for $\mathrm{C}_{16} \mathrm{H}_{15} \mathrm{O}_{2} \mathrm{~S}$, 271.0793; found 271.0794.

\subsubsection{Synthesis of 2,3-Dihydro-2-phenyl-4H-naphtho[1,2-b]thiopyran-4-one (3Pa)}

Employing General Procedure A, using phenylmagnesium bromide $(2.8 \mathrm{M}, 0.19 \mathrm{~mL}, 0.53 \mathrm{mmol})$ and thiochromone $(75 \mathrm{mg}, 0.354 \mathrm{mmol}$ ), after purification by flash column chromatography (silica gel, 0-2\% ethyl acetate: hexanes, $v / v)$, gave a light-yellow solid 3Pa (82 mg, 80\%): $\mathrm{mp} 144.0-145.0{ }^{\circ} \mathrm{C}$; IR (neat) $3057(\mathrm{w}), 3031(\mathrm{w}), 2020(\mathrm{w}), 1668(\mathrm{w}), 1594(\mathrm{~m}), 1552(\mathrm{w}), 1450(\mathrm{w}), 1326(\mathrm{~m}), 1310(\mathrm{~m}), 1267(\mathrm{~m})$, $1245(\mathrm{~m}), 1165(\mathrm{w}), 1076(\mathrm{w}), 810(\mathrm{~m}), 771(\mathrm{~m}), 746(\mathrm{~m}) \mathrm{cm}^{-1},{ }^{1} \mathrm{H}$ NMR $\left(400 \mathrm{MHz}, \mathrm{CDCl}_{3}\right) \delta 3.21(\mathrm{dd}$, $J=2.8,16.4 \mathrm{~Hz}, 1 \mathrm{H}), 4.35(\mathrm{dd}, J=13.6,16.4 \mathrm{~Hz}, 1 \mathrm{H}), 4.74(\mathrm{dd}, J=3.2,13.6 \mathrm{~Hz}, 1 \mathrm{H}), 7.28-7.39(\mathrm{~m}$, $3 \mathrm{H}), 7.41-7.46(\mathrm{~m}, 1 \mathrm{H}), 7.46-7.51(\mathrm{~m}, 1 \mathrm{H}), 7.52-7.58(\mathrm{~m}, 1 \mathrm{H}), 7.73-7.78(\mathrm{~m}, 1 \mathrm{H}), 8.10-8.17(\mathrm{~m}, 2 \mathrm{H}) ;{ }^{13} \mathrm{C}$ NMR $\left(100 \mathrm{MHz}, \mathrm{CDCl}_{3}\right) \delta 45.4,45.8,124.1,125.1,125.4,126.8,127.6,127.7,128.6,128.7,129.1,129.2$, 
130.1, 135.5, 138.4, 142.9, 194.6; HRMS (EI-ion trap) $m / z$ : $[\mathrm{M}+1]^{+}$calcd for $\mathrm{C}_{19} \mathrm{H}_{15} \mathrm{OS}$, 291.0844; found 291.0847.

\subsubsection{Synthesis of 3-Chloro-2-(2-naphthyl)-4H-thiochromen-4-one (4Af)}

To a dichloromethane (DCM) solution of 2-(2-naphthyl)thiochroman-4-one (1.0 equivalent, 0.542 mmol, $157.2 \mathrm{mg}$ ), NCS ( $\mathrm{N}$-chlorosuccinimide) (3.0 equivalent, $1.63 \mathrm{mmol}, 217 \mathrm{mg}$ ) was added. The reaction mixture was stirred at room temperature overnight $(12 \mathrm{~h})$. It was then quenched with water $(10 \mathrm{~mL})$ and extracted with DCM $(3 \times 10 \mathrm{~mL})$. The organic layers were combined and dried over anhydrous $\mathrm{Na}_{2} \mathrm{SO}_{4}$. It was filtered and concentrated in vacuum. The crude product was purified by flash column chromatography (silica gel, $5 \%$ ethyl acetate: hexanes, $v / v$ ) to give $4 \mathrm{Af}$ as a white solid (119 mg, 68\%): mp 161.0-162.0 ${ }^{\circ} \mathrm{C}$; IR (neat) 3052 (w), $2922(\mathrm{w}), 1621$ (s), 1586 (s) $1562(\mathrm{~m}), 1500(\mathrm{w})$, $1462(\mathrm{w}), 1435(\mathrm{w}), 1320(\mathrm{w}), 1305(\mathrm{w}), 1272(\mathrm{w}), 1135(\mathrm{w}), 1112(\mathrm{w}), 851(\mathrm{~m}), 839(\mathrm{~m}), 735(\mathrm{~m}) \mathrm{cm}^{-1} ;{ }^{1} \mathrm{H}$ NMR (400 MHz, CDCl $)$ \& 7.48-7.63 (m, $6 \mathrm{H}), 7.82-7.88(\mathrm{~m}, 2 \mathrm{H}), 7.90(\mathrm{~d}, J=8.4 \mathrm{~Hz}, 1 \mathrm{H}), 7.96(\mathrm{t}, J=0.8$ $\mathrm{Hz}, 1 \mathrm{H}), 8.57(\mathrm{ddd}, J=0.8,1.6,8.0 \mathrm{~Hz}, 1 \mathrm{H}) ;{ }^{13} \mathrm{C} \mathrm{NMR}\left(100 \mathrm{MHz}, \mathrm{CDCl}_{3}\right) \delta 125.6,125.9,126.5,127.0$, $127.7,127.9,128.1,128.5,128.6,128.7,129.8,130.5,131.9,132.6,132.8,133.7,136.6,148.4,174.8$; HRMS (EI-ion trap) $m / z:[\mathrm{M}+1]^{+}$calcd for $\mathrm{C}_{19} \mathrm{H}_{12} \mathrm{OSCl}$, 323.0297; found 323.0296.

\subsubsection{Synthesis of 2-(4-Methoxyphenyl)thiochroman-4-one 1,1-dioxide (5Ac)}

To a dry DCM solution of 2-(4-methoxyphenyl)thiochroman-4-one (94 mg, $0.348 \mathrm{mmol}$ ) under Ar atmosphere in a 50-mL RB flask, excess 3-meta-chloroperoxybenzoic acid ( $m$-CPBA, 3.0 equivalent, $180 \mathrm{mg}, 1.04 \mathrm{mmol}$ ) was added. The resultant mixture was stirred at room temperature until the reaction was complete by TLC monitoring $(4-5 \mathrm{~h})$. Then the reaction mixture was quenched with $\mathrm{NaHCO}_{3}(10 \mathrm{~mL})$ and diluted with DCM $(10 \mathrm{~mL})$. The organic layers were separated and the aqueous layer was extracted with DCM $(2 \times 10 \mathrm{~mL})$. The organic layers were combined and washed with brine and dried over anhydrous $\mathrm{Na}_{2} \mathrm{SO}_{4}$. It was filtered and concentrated in vacuum. The crude product was purified by flash column chromatography (silica gel, $20 \%$ ethyl acetate: hexanes, $v / v$ ) to give a white solid 5Ac (78 mg, 74\%): mp 163-164 ${ }^{\circ} \mathrm{C}$; IR (neat) $3100(\mathrm{w}), 2902(\mathrm{w}), 1690(\mathrm{~s}), 1587(\mathrm{w}), 1376$ (m), 1312 (m), 1273 (s), 1150 (m), 1115 (s), 934 (m), 904 (m), 759 (m) cm ${ }^{-1} ;{ }^{1} \mathrm{H}$ NMR (400 MHz, CDCl 3 ) 3.41 $(\mathrm{dd}, J=3.2,17.61 \mathrm{H}), 3.85(\mathrm{~s}, 3 \mathrm{H}), 3.95(\mathrm{dd}, J=12.8,17.6 \mathrm{~Hz}, 1 \mathrm{H}), 4.85(\mathrm{dd}, J=3.2,12.8 \mathrm{~Hz}, 1 \mathrm{H}), 7.00$ $(\mathrm{dd}, J=2,6.8 \mathrm{~Hz} 1 \mathrm{H}), 7.42(\mathrm{dd}, J=2,6.8 \mathrm{~Hz}, 2 \mathrm{H}), 7.78(\mathrm{td}, J=1.2,8 \mathrm{~Hz}, 1 \mathrm{H}), 7.85(\mathrm{td}, J=1.2,8.0 \mathrm{~Hz}, 1$ $\mathrm{H}), 8.10(\mathrm{dd}, J=1.2,8.0 \mathrm{~Hz}, 1 \mathrm{H}), 8.19(\mathrm{dd}, J=1.2,8 \mathrm{~Hz}, 1 \mathrm{H}) ;{ }^{13} \mathrm{C} \mathrm{NMR}\left(100 \mathrm{MHz}, \mathrm{CDCl}_{3}\right) \delta 43.2,55.4$, 63.5, 114.6, 119.7, 124.5, 128.7, 130.6, 131.1, 133.3, 135.1, 141.5, 160.9, 191.1; HRMS (EI-ion trap) $m / z$ : $[\mathrm{M}+1]^{+}$calcd for $\mathrm{C}_{16} \mathrm{H}_{15} \mathrm{O}_{4} \mathrm{~S}, 303.0691$; found 303.0699.

\subsubsection{Synthesis of 2-[3,5-(Trifluoromethyl)phenyl]thiochroman-4-one 1,1-dioxide (5Ae)}

To a dry DCM solution of 2-[3,5-(trifluoromethyl)phenyl]thiochroman-4-one (116 mg, $0.308 \mathrm{mmol}$ ) under Ar atmosphere in a 50-mL RB flask, excess 3-meta-chloroperoxybenzoic acid (mCPBA, 3.0 equivalent, $0.924 \mathrm{mmol}, 159 \mathrm{mg}$, mCPBA was $70-75 \%$ ) was added. The resultant mixture was stirred at room temperature until the reaction was complete by TLC monitoring $(4-5 \mathrm{~h})$. Then, the reaction mixture was quenched with $\mathrm{NaHCO}_{3}(10 \mathrm{~mL})$ and diluted with DCM $(10 \mathrm{~mL})$. The organic layers were separated and the aqueous layer was extracted with DCM $(2 \times 10 \mathrm{~mL})$. The organic layers were combined and washed with brine and dried over anhydrous $\mathrm{Na}_{2} \mathrm{SO}_{4}$. It was filtered and concentrated in vacuum. The crude product was purified by flash column chromatography (silica gel, $20 \%$ ethyl acetate: hexanes, $v / v)$ to give a white solid $5 \mathrm{Ae}(88 \mathrm{mg}, 70 \%): \mathrm{mp} 162-163^{\circ} \mathrm{C}$; IR (neat) $3100(\mathrm{w}), 2902$ (w), $1690(\mathrm{~s}), 1627(\mathrm{w}), 1587(\mathrm{w}), 1469(\mathrm{w}), 1376(\mathrm{~m}), 1313(\mathrm{~s}), 1273(\mathrm{~s}), 1199(\mathrm{~m}), 1115(\mathrm{~s}), 1038(\mathrm{w}), 934$ (m), $904(\mathrm{~m}), 844(\mathrm{w}), 780(\mathrm{w}), 759(\mathrm{~s}), 706(\mathrm{w}), 679(\mathrm{w}) \mathrm{cm}^{-1},{ }^{1} \mathrm{H}$ NMR $\left(400 \mathrm{MHz}, \mathrm{CDCl}_{3}\right) \delta 3.36$ (dd, $J=3.2,17.61 \mathrm{H}), 3.92(\mathrm{dd}, J=13.2,17.6 \mathrm{~Hz}, 1 \mathrm{H}), 4.94(\mathrm{dd}, J=3.2,12.8 \mathrm{~Hz}, 1 \mathrm{H}), 7.74(\mathrm{dt}, J=1.6,7.6 \mathrm{~Hz}$, $1 \mathrm{H}), 7.89(\mathrm{~s}, 1 \mathrm{H}), 7.93(\mathrm{~s}, 1 \mathrm{H}), 8.01(\mathrm{dd}, J=1.2,8.0 \mathrm{~Hz}, 1 \mathrm{H}), 8.13(\mathrm{dd}, J=1.2,8.0 \mathrm{~Hz}, 1 \mathrm{H}) ;{ }^{13} \mathrm{C} \mathrm{NMR}$ $\left(100 \mathrm{MHz}, \mathrm{CDCl}_{3}\right) \delta 42.6,63.1,121.5,122.8(\mathrm{q}, J=258 \mathrm{~Hz}), 124.2,124.5,129.1,130.0,(\mathrm{~d}, J=3 \mathrm{~Hz}), 130.3$, 
130.7, $132.6(\mathrm{q}, J=34 \mathrm{~Hz}), 133.9,135.4,140.7,189.4 ;{ }^{19} \mathrm{~F} \mathrm{NMR}\left(376 \mathrm{MHz}, \mathrm{CDCl}_{3}\right) \delta-62.9$; HRMS (EI-ion trap) $m / z:[\mathrm{M}+1]^{+}$calcd for $\mathrm{C}_{17} \mathrm{H}_{11} \mathrm{O}_{3} \mathrm{SF}_{6}, 409.0333$; found 409.0333 .

\subsubsection{Synthesis of 2-(2-Methylphenyl)thiochroman-4-ol (7Ab)}

To a dry ethanol solution $(3.0 \mathrm{~mL}$ ) of 2-(2-methylphenyl)thiochroman-4-one (50 mg, $1.0 \mathrm{eq}$, $0.197 \mathrm{mmol}, 50 \mathrm{mg}$ ) under argon, sodium borohydride ( $5 \mathrm{mg}, 0.6 \mathrm{eq}, 0.12 \mathrm{mmol}, 10 \mathrm{mg}$ ) was added portion-wise. The resultant mixture was stirred at room temperature for $2 \mathrm{~h}$ when TLC monitoring showed that all the starting material was gone. Then solvent was evaporated, ice water $(10 \mathrm{~mL})$ was added, and the mixture was acidified with $10 \% \mathrm{HCl}$ to $\mathrm{pH}=1-2$. It was then extracted with ethyl acetate $(3 \times 10 \mathrm{~mL})$ and organic layers were combined, and washed with brine $(15 \mathrm{~mL})$. The organic layer was dried $\left(\mathrm{Na}_{2} \mathrm{SO}_{4}\right)$, filtered, and evaporated under vacuum to give the crude product. The crude product was then purified by flash column chromatography (silica gel, $10 \%$ ethyl acetate: hexanes, $v / v$ ) to give 2-(2-methylphenyl)thiochroman-4-ol $7 \mathrm{Ab}$ as a white solid (41 $\mathrm{mg}, 81 \%)$ : $\mathrm{mp} 146-147{ }^{\circ} \mathrm{C}$; IR (neat) 3269 (sb), $3064(\mathrm{w}), 3021(\mathrm{w}), 2918(\mathrm{~s}), 1953(\mathrm{w}), 1916(\mathrm{w}), 1590(\mathrm{w}), 1565(\mathrm{w}), 1487(\mathrm{~m}), 1486(\mathrm{~s})$, 1435 (m), 1244 (w0, 1220 (w), 1063 (m), 1021 (m), 753 (s) cm ${ }^{-1} ;{ }^{1} \mathrm{H}$ NMR $\left(400 \mathrm{MHz}, \mathrm{CDCl}_{3}\right) \delta 2.0$ (s, $1 \mathrm{H}), 2.47(\mathrm{~s}, 3 \mathrm{H}), 2.48-2.53(\mathrm{~m}, 1 \mathrm{H}), 2.67(\mathrm{ddd}, J=2.8,5.2,12.8 \mathrm{~Hz}, 1 \mathrm{H}), 4.86(\mathrm{dd}, J=3.2,12 \mathrm{~Hz}, 1 \mathrm{H})$, 5.0-5.10 (m, $1 \mathrm{H}), 7.11-7.28(\mathrm{~m}, 6 \mathrm{H}), 7.49-7.55(\mathrm{~m}, 1 \mathrm{H}), 7.65-7.73(\mathrm{~m}, 6 \mathrm{H}) ;{ }^{13} \mathrm{C} \mathrm{NMR}\left(100 \mathrm{MHz}, \mathrm{CDCl}_{3}\right)$

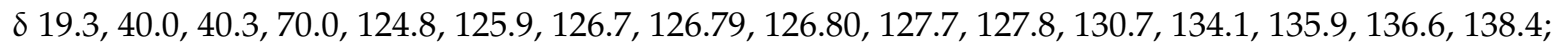
HRMS (EI-ion trap) $m / z$ : [M + Na] ${ }^{+}$calcd for $\mathrm{C}_{16} \mathrm{H}_{16} \mathrm{ONaS}$, 279.0820; found 279.0826.

\section{Conclusions}

In conclusion, we successfully developed the conjugate addition of Grignard reagents to thiochromones catalyzed by $\mathrm{CuCN} \cdot 2 \mathrm{LiCl}$ in the presence of chlorotrimethylsilane (TMSCl) as an activator to afford 2-alkylthiochroman-4-ones and thioflavanones (2-arylthiochromon-4-ones) in good yields. This reaction was shown to work well with a broad range of Grignard reagents, both alkyl and aromatic Grignard reagents. This synthetic approach will allow access to a broader scope of thiochromanones and thioflavanones due to the readily available Grignard reagents compared to organolithium reagents. Very interesting compounds, such as 6,8-difluorosubstituted thiochroman-4-ones, were synthesized for further studies. The 1,4-adducts, both 2-alkylthiochroman-4-ones and thioflavanones, can be utilized for additional synthetic applications and provide quick access that privileges sulfur-heterocycles.

Supplementary Materials: The following are available online.

Author Contributions: T.J.B., T.H., T.P.-F., N.A., S.H.W., M.L.C.T.Y.T., D.T.H., and N.D. performed the experiments. F.G. conceived and designed the experiments; F.G. wrote the paper. All authors have read and agreed to the published version of the manuscript.

Funding: This research was funded by NSF HBCU-UP RIA, grant number 1600987 and NSF EiR, grant number 1831339. Part of this research was funded NIH RISE, and grant number R25GM113774. Tania J. Bellinger, Nataleigh Austin, Mai Ling Yuk Tutein, and Nichele Deese are NIH RISE scholars. We like to thank NSF CUR-TP team (NSF, grant 1625354) for supporting the re-design of CH3236 (I\&R) and the undergraduate transformation project. The APC was funded by NSF HBCU-UP RIA, grant number 1600987 . We also like to thank Dr. Marcus Wright from Chemistry Department, Wake Forest University, Winston Salem for access to NMR facility and assistance in attaining NMR spectra. We thank WSSU Provost's Office for supporting the re-design of CH3236 (I\&R). This is also part of the project that Mai Ling Tang Yuk Tutein, Ti'Bran Pickens-Flynn and Nataleigh Austin are working on for CH3236 (I\&R) and CH4244 (Directed Research) courses, backward redesigned I\&R and directed research, part of the NSF Council of Undergraduate Research Transformation Project.

Conflicts of Interest: The authors declare no conflict of interest. 


\section{References}

1. Ortiz, P.; Lanza, F.; Harutyunyan, S.R. 1,2- Versus 1,4-Asymmetric Addition of Grignard Reagents to Carbonyl Compounds. In Progress in Enantioselective Cu(I)-catalyzed Formation of Stereogenic Centers; Harutyunyan, S.R., Ed.; Springer Press: Basel, Switzerland, 2016; pp. 99-134.

2. Kharasch, M.S.; Tawney, P.O. Factors Determining the Course and Mechanisms of Grignard Reactions. II. The Effect of Metallic Compounds on the Reaction between Isophorone and Methylmagenisum Bromide. J. Am. Chem. Soc. 1941, 63, 2308-2316. [CrossRef]

3. Damani, L.A. (Ed.) Sulphur-Containing Drugs and Related Organic Compounds; Wiley: New York, NY, USA, 1989.

4. Clayden, J.; MacLellan, P. Asymmetric synthesis of tertiary thiols and thioethers. Beilstein J. Org. Chem. 2011, 7, 582-595. [CrossRef] [PubMed]

5. Ingall, A.H. Thiopyrans and Fused Thiopyrans. In Comprehensive Heterocyclic Chemistry; Katritzky, A.R., Rees, C.W., Eds.; Pergamon Press: Oxford, UK, 1984; Volume 3, p. 885.

6. Schneller, S.W. Thiochromanones and Related Compounds. In Advances in Heterocyclic Chemistry; Katritzky, A.R., Boulton, A.J., Eds.; Academic Press: New York, USA, 1975; Volume 18, p. 59.

7. Acton, A.Q. (Ed.) Sulfur Compounds: Advances in Research and Application; Scholarly Editions: Atlanta, GA, USA, 2012.

8. Nielsen, S.F.E.; Nielsen, O.; Olsen, G.M.; Liljefors, T.; Peters, D. Novel Potent Novel Potent Ligands for the Central Nicotinic Acetylcholine Receptor: Synthesis, Receptor Binding, and 3D-QSAR Analysis. J. Med. Chem. 2000, 43, 2217-2226. [CrossRef] [PubMed]

9. Smith, B.R.; Eastman, C.M.; Njardarson, J.T. Beyond C, H, O and N! Analysis of the Elemental Composition of U.S. FDA Approved Drug Architectures. J. Med. Chem. 2014, 57, 9764-9773. [CrossRef] [PubMed]

10. Takimiya, K.; Osaka, I.; Mori, T.; Nakano, M. Organic Semiconductors Based on [1]Benzothieno[3,2-b][1]benzothiophene Substructure. Acc. Chem. Res. 2014, 47, 1493-1502. [CrossRef] [PubMed]

11. Joyce, N.I.; Eady, C.C.; Silcock, P.; Perry, N.B.; Van Klink, J.W. Fast Phenotyping of LFS-Silenced (Tearless) Onions by Desorption Electrospray Ionization Mass Spectrometry (DESI-MS). J. Agric. Food Chem. 2013, 61, 1449-1456. [CrossRef] [PubMed]

12. Mishra, A.; Ma, C.Q.; Bauerle, P. Functional Oligothiophenes: Molecular Design for Multidimensional Nanoarchitectures and Their Applications. Chem. Rev. 2009, 109, 1141-1276. [CrossRef]

13. Lin, D.Y.; Zhang, S.Z.; Block, E.; Katz, L.C. Encoding social signals in the mouse main olfactory bulb. Nature 2005, 434, 470-477. [CrossRef]

14. Wermuch, C.G. Molecular variations based on isosteric replacements. In The Practice of Medicinal Chemistry; Wermuth, C.G., Ed.; Academic Press: San Diego, CA, USA, 1996; pp. 203-237.

15. Choi, E.J.; Lee, J.I.; Kim, G.-H. Evaluation of the anticancer activities of thioflavanone and thioflavone in human breast cancer cell lines. Int. J. Mol. Med. 2012, 29, 252-256.

16. Vargas, E.; Echeverri, F.; Vélez, I.D.; Robledo, S.M.; Quiňones, W. Synthesis and Evaluation of Thiochroman-4-one Derivatives as Potential Leishmanicidal Agents. Molecules 2017, 22, 2041. [CrossRef]

17. Zhao, J.; Li, H.-Z.; Suo, H.; Wang, Y.; Yang, C.; Ma, Z.; Liu, Y. Cytoxic effect of three novel thiochromanone derivatives on tumor cell in vitro and underlying mechanism. Glob. Adv. Res. J. Med. Sci. 2014, 3, 240-250.

18. Harborne, J.B. The Flavonoids: Advances in Research Since 1980; Chapman and Hall: New York, NY, USA, 1988.

19. Harborne, J.B.; Williams, C.A. Anthocyanins and other flavonoids. Nat. Prod. Rep. 1995, 12, 639-657. [CrossRef]

20. Pietta, P.G. Flavonoids as antioxidants. J. Nat. Prod. 2000, 63, 1035-1042. [CrossRef] [PubMed]

21. Andersen, O.M.; Markham, K.R. (Eds.) Flavonoids: Chemistry, Biochemistry and Applications; Taylor \& Francis: London, UK, 2006.

22. Philipp, A.; Jirkovsky, I.; Martel, R.R. Synthesis and antiallergic properties of some $4 H ， 5 H$-pyrano[3,2-c][1]benzopyran-4-one, $\quad 4 H, 5 H$-[1]benzothiopyrano[4,3- $b]$ pyran-4-one, $\quad$ and 1,4-dihydro-5H-[1]benzothiopyrano[4,3-b]pyridine-4-one derivatives. J. Med. Chem. 1980, 23, 1372-1376. [CrossRef]

23. Ramalingam, K.; Thyvelikakath, G.X.; Berlin, K.D.; Chesnut, R.W.; Brown, R.A.; Durham, N.N.; Ealick, S.E.; Van der Helm, D. Synthesis and biological activity of some derivatives of thiochroman-4-one and tetrahydrothiapyran-4-one. J. Med. Chem. 1977, 20,847-850. [CrossRef] 
24. Wang, H.K.; Bastow, K.F.; Cosentino, L.M.; Lee, K.H. Antitumor Agents. 166. Synthesis and Biological Evaluation of 5,6,7,8-Substituted-2-phenylthiochromen-4-ones. J. Med. Chem. 1996, 39, 1975-1980. [CrossRef]

25. Holshouser, M.H.; Loeffler, L.J.; Hall, I.H. Synthesis of peptides by the solid-phase method. 6. Neurotensin, fragments, and analogs. J. Med. Chem. 1981, 24, 853-858. [CrossRef]

26. Dhanak, D.; Keenan, R.M.; Burton, G.; Kaura, A.; Darcy, M.G.; Shah, D.H.; Ridgers, L.H.; Breen, A.; Lavery, P.; Tew, D.G.; et al. Benzothiopyran-4-one based reversible inhibitors of the human cytomegalovirus (HCMV) protease. Bioorg. Med. Chem. Lett. 1998, 8, 3677-3682. [CrossRef]

27. Nussbaumer, P.; Lehr, P.; Billich, A. 2-Substituted 4-(Thio)chromenone 6-O-Sulfamates: Potent Inhibitors of Human Steroid Sulfatase. J. Med. Chem. 2002, 45, 4310-4320. [CrossRef]

28. Kataoka, T.; Watanabe, S.; Mori, E.; Kadomoto, R.; Tanimura, S.; Kohno, M. Synthesis and structure-activity relationships of thioflavone derivative as specific inhibitors of the ERK-MAP kinase signaling pathway. Bioorg. Med. Chem. 2004, 12, 2397-2407. [CrossRef]

29. Soni, D.V.; Jacobberger, J.W. Gene modulation by Cox-1 and Cox-2 specific inhibitors in human colorectal carcinoma cancer cells. Cell Cycle 2004, 3, 349-357. [PubMed]

30. Bondock, S.; Metwally, M.A. Thiochroman-4-ones: Synthesis and reactions. J. Sulfur Chem. 2008, 29, $623-653$. [CrossRef]

31. Dalla Via, L.; Marciani Magno, S.; Gia, O.; Marini, A.M.; Da Settimo, F.; Salerno, S.; La Motta, C.; Simorini, F.; Taliani, S.; Lavecchia, A.; et al. Benzothiopyranoindole-Based Antiproliferative Agents: Synthesis, Cytoxicity, Nucleic Acids Interaction, and Topoisomerases Inbibition Properties. J. Med. Chem. 2009, 52, 5429-5441. [CrossRef] [PubMed]

32. Bates, D.K.; Li, K. Stannous Chloride-Mediated Reductive Cyclization-Rearrangement of Nitroarenyl Ketones. J. Org. Chem. 2002, 67, 8662-8665. [CrossRef]

33. Aramaki, Y.; Seto, M.; Okawa, T.; Oda, T.; Kanzaki, N.; Shiraishi, M. Synthesis of 1-Benzothiepine and 1-Benzazepine Derivatives as Orally Active CCR5 Antagonists. Chem. Pharm. Bull. 2004, 52, 254-258. [CrossRef]

34. Dike, S.Y.; Ner, D.H.; Kumar, A. A New Enantioselective Chemoenzymatic Synthesis of R-(-)Thiazesim Hydrochloride. Bioorg. Med. Chem. Lett. 1991, 1, 383-386. [CrossRef]

35. Phippen, C.B.W.; McErlean, C.S.P. A 1,5-Benzothiazepine Synthesis. Tetrahedron Lett. 2011, 52, $1490-1492$. [CrossRef]

36. Li, W.; Schlepphorst, C.; Daniliuc, C.; Glorius, F. Asymmetric Hydrogenation of Vinylthioethers: Access to Optically Active 1,5-Benzothiazepine Derivatives. Angew. Chem. Int. Ed. 2016, 55, 3300-3303. [CrossRef]

37. Fang, X.; Li, J.; Wang, C.J. Organocatalytic Asymmetric Sulfa-Michael Addition of Thiols to $\alpha, \beta$-Unsaturated Hexafluoroisopropyl Esters: Expeditious Access to (R)-Thiazesim. Org. Lett. 2013, 15, 3448-3451. [CrossRef]

38. Fukata, Y.; Asano, K.; Matsubara, S. Facile Net Cycloaddition Approach to Optically Active 1,5-Benzothiazepines. J. Am. Chem. Soc. 2015, 137, 5320-5323. [CrossRef]

39. Qi, X.; Xiang, H.; Yang, C. Synthesis of Functionalized Chromeno[2,3- $b$ ]pyrrol-4(1H)-ones by Silver-Catalyzed Cascade Reactions of Chromones/Thiochromones and Isocyanoacetates. Org. Lett. 2015, 17, 5590-5593. [CrossRef] [PubMed]

40. Ali, A.; Ahmad, V.U.; Liebscher, J. Stereoselective Synthesis of Thiochroman-4-ones by Ring Transformation of Chiral 5-Ylidene-1,3-dioxan-4-ones with 2-Bromothiophenol via Bromo-Lithium Exchange. Eur. J. Org. Chem. 2001, 2001, 529-535. [CrossRef]

41. Vaghoo, H.; Prakash, G.K.; Narayanan, A.; Choudhary, R.; Paknia, F.; Mathew, T.; Olah, G.A. Superelectrophilic Activation of Crotonic/Methacrylic Acids: Direct Access to Thiochroman-4-ones from Benzenethiols by Microwave-Assisted One-Pot Alkylation/Cyclic Acylation. Org. Lett. 2015, 17, 6170-6173. [CrossRef] [PubMed]

42. Cui, D.-M.; Kawamura, M.; Shimada, S.; Hayashi, T.; Tanaka, M. Synthesis of 1-Tetralones by Intramolecular Friedel-Crafts Reaction of 4-Arylbutyric Acids Using Lewis Acid Catalysts. Tetrahedron Lett. 2003, 44, 4007-4010. [CrossRef]

43. Hoettecke, N.; Rotzoll, S.; Albrecht, U.; Lalk, M.; Fischer, C.; Langer, P. Synthesis and Antimicrobial Activity of 2-Alkenylchroman-4-ones, 2-Alkenylthiochroman-4-ones and 2-Alkenylquinol-4-ones. Bioorg. Med. Chem. 2008, 16, 10319-10325. [CrossRef]

44. Dong, X.Q.; Fang, X.; Wang, C.J. Organocatalytic Asymmetric Sulfa-Michael Addition of Thiols to 4,4,4-Trifluorocrotonates. Org. Lett. 2011, 13, 4426-4429. [CrossRef] 
45. Xiao, W.-J.; Alper, H. Regioselective Carbonylative Heteroannulation of o-Iodothiophenols with Allenes and Carbon Monoxide Catalyzed by a Palladium Complex: A Novel and Efficient Access to Thiochroman-4-one Derivatives. J. Org. Chem. 1999, 64, 9646-9652. [CrossRef]

46. Dawood, K.M.; Ishii, H.; Fuchigami, T. Electrolytic Partial Fluorination of Organic Compound. 54.1 Anodic Mono- and Trifluorination of Thiochroman-4-one Derivatives and the Factors Affecting Product Selectivity. J. Org. Chem. 2001, 66, 7030-7034. [CrossRef]

47. Palani, T.; Park, K.; Song, K.H.; Lee, S. Palladium-Catalyzed Synthesis of (Z)-3-Arylthioacrylic Acids and Thiochromenones. Adv. Synth. Catal. 2013, 355, 1160-1168. [CrossRef]

48. Han, X.; Yue, Z.; Zhang, X.; He, Q.; Yang, C. Copper-Mediated, Palladium-Catalyzed Cross-Coupling of 3-Iodochromones, Thiochromones, and Quinolones with Ethyl Bromodifluoroacetate. J. Org. Chem. 2013, 78, 4850-4856. [CrossRef]

49. Inami, T.; Kurahashi, T.; Matsubara, S. Nickel-Catalyzed Reaction of Thioisatins and Alkynes: A Facile Synthesis of Thiochromones. Org. Lett. 2014, 16, 5660-5662. [CrossRef] [PubMed]

50. Muthupandi, P.; Sundaravelu, N.; Sekar, G. Domino Synthesis of Thiochromenes through Cu-Catalyzed Incorporation of Sulfur Using Xanthate Surrogate. J. Org. Chem. 2017, 82, 1936-1942. [CrossRef] [PubMed]

51. Meng, L.; Jin, M.; Wang, J. Rh-Catalyzed Conjugate Addition of Arylzinc Chlorides to Thiochromones: A Highly Enantioselective Pathway for Accessing Chiral Thioflavanones. Org. Lett. 2016, 18, 4986-4989. [CrossRef] [PubMed]

52. Xiong, D.; Zhou, W.; Lu, Z.; Zeng, S.; Wang, J. A highly enantioselective access to chiral chromanones and thiochromanones via copper-catalyzed asymmetric conjugated reduction of chromones and thiochromones. Chem. Comm. 2017, 53, 6844-6847. [CrossRef]

53. Lee, J.I. New Synthesis of Thioflavanones by the Regioselective Cyclization of 1-(2-Benzylthio)phenyl-3-phenyl-2-propen-1-ones with Hydrobromic Acid. Bull. Korean Chem. Soc. 2020, 41, 484-487. [CrossRef]

54. Lemke, M.K.; Schwab, P.; Fischer, P.; Tischer, S.; Witt, M.; Noehringer, L.; Rogachev, V.; Jager, A.; Kataeva, O.; Frohlich, R.; et al. A Practical Access to Highly Enantiomerically Pure Flavanones by Catalytic Asymmetric Transfer Hydrogenation. Angew. Chem. Int. Ed. 2013, 52, 11651-11655. [CrossRef]

55. Zhao, D.-B.; Beiring, B.; Glorius, F. Ruthenium-NHC-catalyzed Asymmetric Hydrogenation of Flavones and Chromones: General Access to Enantiomerically Enriched Flavanones, Flavanols, Chromanones, and Chromanols. Angew. Chem. Int. Ed. 2013, 52, 8454-8458. [CrossRef]

56. Kumar, P.; Rao, A.T.; Pandey, B. Chemoselective Reduction of Vinylogous Thioesters of Thiochromones. Synth. Commun. 1994, 24, 3297-3306. [CrossRef]

57. Sakirolla, R.; Yaeghoobi, M.; Abd Rahman, N. Synthesis of Flavanones, Azaflavanones, and Thioflavanones Catalyzed by PMA-SiO 2 as a Mild, Efficient, and Reusable Catalyst. Monatsh. Chem. 2012, 143, 797-800. [CrossRef]

58. Kobayashi, K.; Kobayashi, A.; Tanmatsu, M. A Facile Synthesis of 2-Arylthiochroman-4-ones by the Reaction of 3-Aryl-1-(2-halophenyl)prop-2-en-1-ones with Sodium Hydrogensulfide. Heterocycles 2012, 85, 919-925. [CrossRef]

59. Sangeetha, S.; Muthupandi, P.; Sekar, G. Copper-Catalyzed Domino Synthesis of 2-Arylthiochromanones through Concomitant C-S Bond Formations Using Xanthate as Sulfur Source. Org. Lett. 2015, 17, 6006-6009. [CrossRef] [PubMed]

60. Konieczny, W.; Konieczny, M. Synthesis of Thioflavanone and Flavanone Derivatives by Cyclization of Chalcones. Synthesis 2009, 1811-1814. [CrossRef]

61. Lee, J.I. A New Synthesis of Thioflavanones from Thiosalicylic Acid. Bull. Korean Chem. Soc. 2008, 29, 1263-1265.

62. Zu, L.; Wang, J.; Li, H.; Xie, H.; Jiang, W.; Wang, W. Cascade Michael-Aldol Reactions Promoted by Hydrogen Bonding Mediated Catalysis. J. Am. Chem. Soc. 2007, 129, 1036-1037. [CrossRef]

63. Konieczny, M.T.; Horowska, B.; Kunikowski, A.; Konopa, J.; Wierzba, K.; Yamada, Y.; Asao, T. Synthesis and Reactivity of 5,8-Dihydroxythioflavanone Derivatives. J. Org. Chem. 1999, 64, 359-364. [CrossRef]

64. Kaye, P.T.; Mphahlele, M.J. Benzodiazepine Analogues. Part 8.1 Trimethylsilyl Azide Mediated Schmidt Rearrangement of Thioflavanone and Thiochromanone Precursors. Synth. Commun. 1995, 25, 1495-1509. [CrossRef] 
65. Bouisseau, A.; Glancy, J.; Willis, M.C. Two-Component Assembly of Thiochroman-4-ones and Tetrahydrothiopyran-4-ones Using Rhodium-Catalyzed Alkyne Hydroacylation/Thio-Conjugate-Addition Sequence. Org. Lett. 2016, 18, 5676-5679. [CrossRef]

66. Bass, S.A.; Parker, D.M.; Bellinger, T.J.; Eaton, A.S.; Dibble, A.S.; Koroma, K.L.; Sekyi, S.A.; Pollard, D.A.; Guo, F. Development of Conjugate Addition of Lithium Dialkylcuprates to Thiochromones: Synthesis of 2-Alkylthiochroman-4-ones and Additional Synthetic Applications. Molecules 2018, 23, 1728. [CrossRef]

67. Guo, F.; Jeffries, M.C.; Graves, B.N.; Graham, S.A.; Pollard, D.A.; Pang, G.; Chen, H.Y. A Rapid Entry Into Thioflavanones via Conjugate Additions of Diarylcuprates to Thiochromones. Tetrahedron 2017, 73, 5745-5750. [CrossRef]

68. Dike, S.Y.; Mahalingam, M. Efficient and Improved Procedure for the Synthesis of 3-Chloro Derivatives of Flavones, Chromones and their Sulfur Analogues. Synthetic Communications 1989, 19, 3443-3451. [CrossRef]

69. Sangeetha, S.; Sekar, G. Copper-Catalyzed One-pot Synthesis of 2-Arylthiochromenones: An in situ Recycle of Waste Byproduct as Useful Reagent. Org. Lett. 2019, 21, 75-79. [CrossRef] [PubMed]

70. French, K.L.; Angel, A.J.; Williams, A.R.; Hurst, D.R.; Beam, C.F. A new preparation of substituted $4 H$-1-benzothiopyran-4-ones from $\mathrm{c}(\alpha) \mathrm{N}$-benzoylbydrazones or $\mathrm{c}(\alpha) \mathrm{N}$-carboalkoxyhydrazones and methyl thiosalicylate. J. Heterocycl. Chem. 1998, 35, 45-48. [CrossRef]

Sample Availability: Samples of the compounds are not available from the authors. 